Quim. Nova, Vol. 25, No. 5, 736-740, 2002

\title{
REDUÇÃO DE POLUENTES DE EFLUENTES DAS INDÚSTRIAS DE PAPEL E CELULOSE PELA FLOCULAÇÃO/COAGULAÇÃO E DEGRADAÇÃO FOTOQUÍMICA
}

\author{
Marcos José de Barros e Jorge Nozaki* \\ Departamento de Química, Universidade Estadual de Maringá, Av. Colombo, 5790, 87020-900 Maringá-PR
}

Recebido em 20/6/01; aceito em 12/12/01

\begin{abstract}
POLLUTANTS ABATEMENT FROM EFFLUENTS OF PAPER AND PULP INDUSTRIES BY FLOCCULATION/ COAGULATION AND PHOTOCHEMICAL DEGRADATION. The abatement of recalcitrant lignin macromolecules from effluents of pulp and paper industry was investigated by combined process. Flocculation and coagulation with aluminum sulfate and natural polyelectrolytes extracted from cactus Cereus peruvianus were used in the first step. After separation of solid residues by filtration, the photochemical methods using $\mathrm{TiO}_{2}$ as catalyst were employed for photocatalytic degradation of lignin compounds from solution. The abatement of lignin compounds after flocculation and coagulation was $46 \%$, and after the overall process, the pollutants reduction observed were $66 \%$. The remaining organic compounds may be removed by any biological treatment.
\end{abstract}

Keywords: flocculation/coagulation; effluents; lignin.

\section{INTRODUÇÃO}

Os efluentes das indústrias de papel e celulose são importantes fontes de poluições das águas. A indústria de papel e polpa de celulose Klabin em Telêmaco Borba - PR, substituiu o processo da cloração como alvejante, pela ozonização. Entretanto, os seus efluentes ainda contribuem com $85 \%$ da cor e $50 \%$ de demanda bioquímica de oxigênio (DBO) total das águas no local da descarga no rio Tibagí. Os efluentes gerados na máquina de papel pela formação e prensagem da folha, denominados de água branca, contribuem para o aumento da demanda química de oxigênio (DQO), devido às fibras celulósicas contendo resíduos de produtos como cola, agentes branqueadores, amidos, etc. Concentrações variadas de ligninas são acrescentadas ao efluente ao longo do processo e, dois pontos de extrações de ligninas são importantes, as fases de polpação e do branqueamento $^{1,2}$. Os efluentes gerados na polpação química contém sólidos em suspensão e materiais orgânicos dissolvidos, compostos ligno-celulósicos, etc ${ }^{2}$.

Quando se utiliza o ozônio a carga poluidora é menor, comparada aos processos de cloração. Porém, derivados de ligninas e carboidratos são liberados e considerados de elevada toxicidade ao meio ambiente. Recentemente, foram investigados os processos oxidativos avançados, baseados na produção de radicais hidroxilas de características oxidantes, como possíveis substitutos dos oxidantes químicos mais poluentes ${ }^{3}$. Foram também investigadas a saturação do efluente com compostos modelos tais como o fenol ${ }^{4}$, ptoluenosulfonato ${ }^{5}$, e outros compostos com grupos semelhantes aos contidos na molécula de lígnina, para verificar e comparar a dinâmica de fotodegradação destes compostos ${ }^{6}$.

A floculação e a coagulação consistem na clarificação das águas pelo arraste do material finamente dividido em suspensão por agentes coagulantes ${ }^{7}$. Apesar da possibilidade de floculação e coagulação somente com os sais de alumínio ou ferro, existem casos em que é necessário o uso de auxiliares de floculação e coagulação. Como auxiliares, os mais usados são os polieletrólitos naturais ou sintéti$\cos ^{8}$.

\footnotetext{
*e-mail: jnozaki@cybertelecom.com.br
}

Os principais objetivos deste trabalho foram:

- utilização dos polieletrólitos naturais extraídos do cactus Cereus peruvianus, como auxiliares de floculação e coagulação;

- investigação da degradação fotoquímica do material não decantado visando, desta forma, a redução de poluentes dos efluentes das indústrias de papel e celulose;

- utilização de um composto modelo, neste caso o fenol, para verificar a dinâmica da degradação sob a ação da radiação fotocatalítica.

\section{PARTE EXPERIMENTAL}

\section{Amostragens}

Foram coletadas no período de janeiro a novembro de 1999, em dois pontos, o efluente da extração alcalina do branqueamento (canal do branqueamento), e na mistura dos efluentes do digestor e do branqueamento (canal central) (Figura 1) ${ }^{9}$. Os recipientes foram bombonas em PVC de $50 \mathrm{~L}$, e foram conservados em temperatura aproximada de $21-23^{\circ} \mathrm{C}$ em sala com ar condicionado, e retiradas alíquotas em quantidades necessárias para os procedimentos experimentais.

\section{Coagulantes e auxiliares de floculação/coagulação}

O sulfato de alumínio e o cloreto férrico foram utilizados como coagulantes. Nos estudos das absorções na região do UV (espectrofotômetros UV-VIS Beckman DU-70 e Hitachi UV-2000), utilizaram-se filtrações prévias para a retirada dos resíduos que não decantaram. As soluções de polieletrólitos naturais foram preparadas a partir da polpa do cactus Cereus peruvianus ${ }^{8}$ na concentração de 100 $\mathrm{mg} \mathrm{L}^{-1}$. Na extração dos polieletrólitos, optou-se pelo método aquoso, que consistiu na eliminação dos espinhos sob a ação do fogo, descascando e retirando as partes polposas e, a seguir, cortadas em cubos, sendo então maceradas e extraídas as partes mucilaginosas ${ }^{1,7}$. Em seguida, pesaram-se $128 \mathrm{~g}$ do material polposo, adicionando-se $150 \mathrm{~mL}$ de água destilada, previamente fervida, deixando a mistura permanecer a $4{ }^{\circ} \mathrm{C}$ por $24 \mathrm{~h}$. A seguir, o extrato viscoso de coloração amareloesverdeada foi coado em peneira para separar o material fibroso de cor transparente, consistindo basicamente de celulose e hemicelulose. 


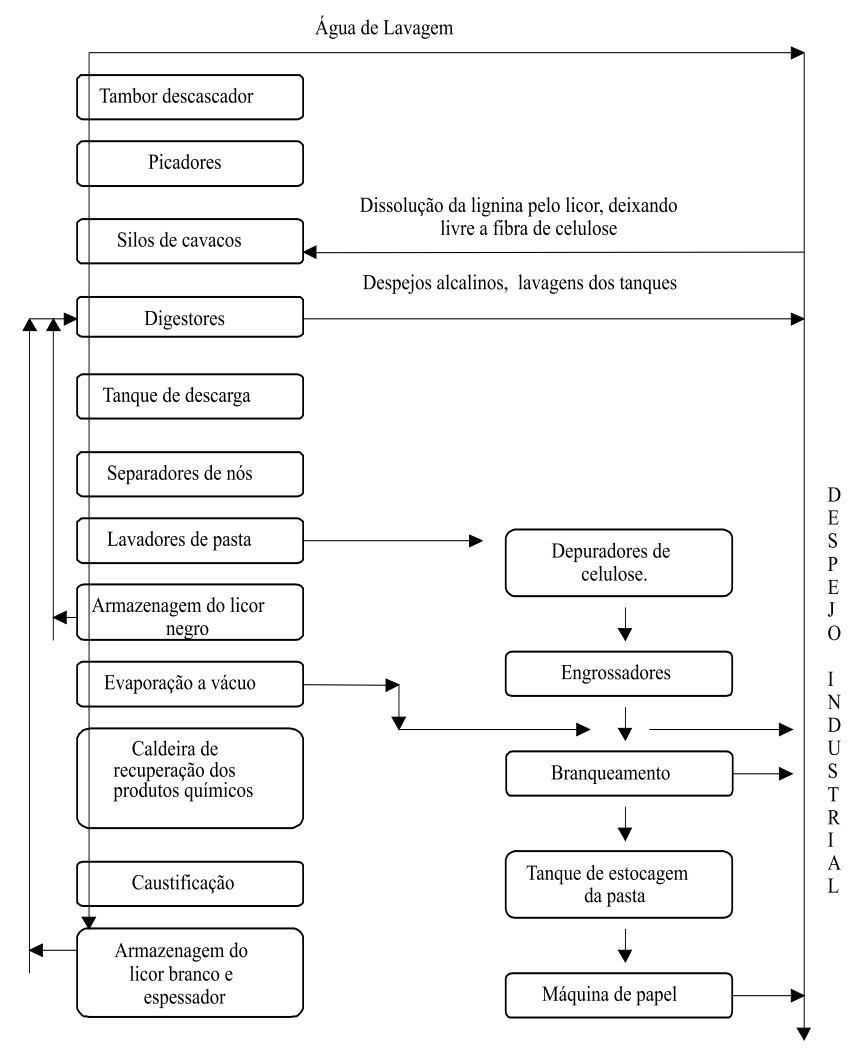

Figura 1. Fluxograma do processo Kraft de fabricação de celulose e papel e a disposição do efluente do canal central e do branqueamento dentro do processo da Klabin S. $A^{6}$. Em negrito aparecem os efluentes investigados (digestores e branqueamento)

\section{Floculação/coagulação-teste de jarros}

Após a determinação da concentração dos polieletrólitos naturais $^{1,7}$, as condições ótimas para este tratamento foram estudadas através do teste de jarros (Jar-Test Milan-101). Adicionaram-se $300 \mathrm{~mL}$ de efluentes, ajustando-se o pH e, após a adição de coagulantes em diferentes concentrações, agitou-se fortemente a amostra a $100 \mathrm{rpm}$ durante $1,5 \mathrm{~min}$ e a $20 \mathrm{rpm}$ por $30 \mathrm{~min}$. Em seguida, adicionaram-se concentrações diferentes de polieletrólitos, desligando-se o aparelho, e deixando-se em repouso por $2 \mathrm{~h}$ para a formação dos flocos. A partir do sobrenadante previamente filtrado foram determinadas as concentrações de compostos aromáticos através das leituras de absorções a comprimento de onda de $280 \mathrm{~nm}$, região de máxima absorção para compostos aromáticos derivados da lignina ${ }^{10,11}$, e também pelas análises da DQO. As concentrações dos coagulantes e os respectivos $\mathrm{pH}$ para a floculação e coagulação foram: $\mathrm{Al}_{2}\left(\mathrm{SO}_{4}\right)_{3}, 100$ a $1000 \mathrm{mg} \mathrm{L}^{-1}$, faixa de $\mathrm{pH}$ entre 4 e $8 ; \mathrm{FeCl}_{3}, 50$ a $500 \mathrm{mg} \mathrm{L}^{-1}$ e pH 5 a 11. Os compostos aromáticos não sedimentados foram estudados pelo tratamento fotoquímico, onde o efluente ainda com uma certa coloração, foi conduzido à calha de tratamento.

\section{Reatores fotoquímicos}

Os reatores foram montados a partir de calhas de aço inox 306 dentro de uma caixa de madeira, com adaptações para a aplicação da radiação no efluente em diferentes alturas (Figura 2). Foram feitos dois furos de 5,0 mm, nas extremidades da caixa, para passar os tubos de silicone para a entrada do afluente e saída do efluente. $\mathrm{Na}$

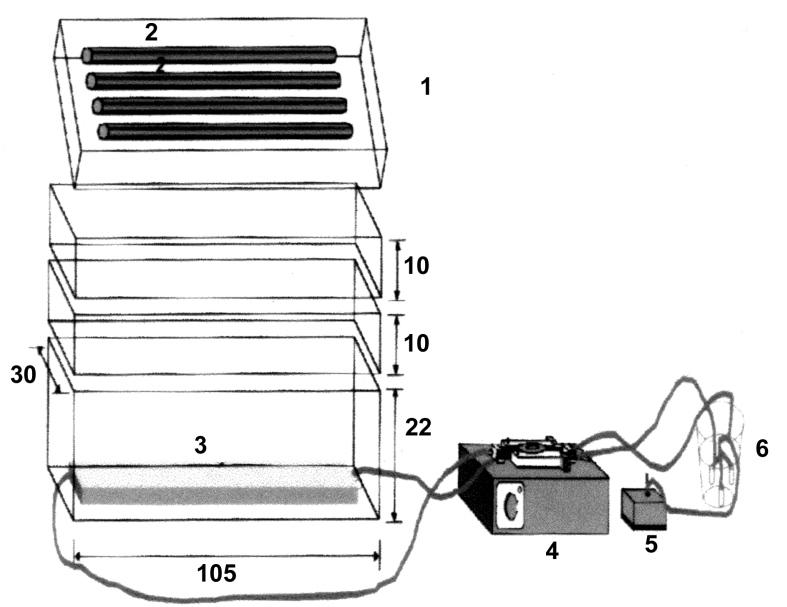

Figura 2. Esquema do reator para a irradiação ultravioleta, e os componentes foram: (1) Tampa e caixa de madeira revestida com papel alumínio, nas medidas descritas $(\mathrm{em} \mathrm{cm}$ ), onde $10 \mathrm{~cm}=$ altura, $30 \mathrm{~cm}=$ largura, $22 \mathrm{~cm}=$ altura da caixa inferior, e $115 \mathrm{~cm}$ era o comprimento da mangueira. (2) Lâmpadas germicidas Ultra Violeta Curta (UVC, l(max.) = $254 \mathrm{~nm})$, no total de 4 lâmpadas com potência resultante de $(4 \times 8=32 \mathrm{We}$ $4 \times 30=120 \mathrm{~W}$ ). (3) Calha de aço inoxidável 306, com controlador da espessura da película. (4) Bomba peristáltica (Milan BP204 de 4 canais). Fluxo ou vazão do efluente $\sim 360 \mathrm{~mL} \mathrm{~h} h^{-1}$. (5) Compressor de ar utilizado em aquários domésticos. (6) Recipiente controlador visual dos fluxos

parte lateral da calha colocou-se um indicador de volume e um béquer de controle da vazão próximo a bomba peristáltica (Milan BP-204), para facilitar também a recirculação do efluente/afluente na calha.

O segundo reator foi constituído pelos mesmos componentes, exceto as lâmpadas que foram de $8 \mathrm{~W}$. Foram investigados os afluentes em fluxo contínuo e em repouso, utilizando-se $2 \mathrm{~L}$ do sobrenadante do processo de coagulação e floculação para reatores de $120 \mathrm{~W}$, e $300 \mathrm{~mL}$ para reatores de $18 \mathrm{~W}$ de lâmpadas UVC e BLB (luz azul negra). No caso do fluxo contínuo, procurou-se manter a velocidade do fluxo em aproximadamente $360 \mathrm{~mL} \mathrm{~h}^{-1}$, com limpezas periódicas das mangueiras. Foram também utilizadas lâmpadas BLB de $16 \mathrm{~W}$ e de vapor metálico de iodetos de ferro e galio com potência de $150 \mathrm{~W}$. O monitoramento dos tratamentos foram realizados através das análises da DQO, infravermelho e ultrafiltração, através das leituras de absorções das soluções sobrenadantes previamente filtradas ${ }^{10-15}$.

\section{Degradação fotoquímica/fotocatalítica e monitoramento do efluente}

Utilizou-se uma solução do fenol como composto modelo para verificar a dinâmica de sua fotodegradação, comparando-se com a degradação do efluente. Foram feitas diluições adequadas da solução de fenol $5 \mathrm{~mol} \mathrm{~L}^{-1}$ com água destilada para o alcance de valores nas absorvâncias iniciais do efluente em que foi saturado.

$\mathrm{O} \mathrm{TiO}_{2}$ anatase e $\mathrm{TiO}_{2}$ e $\mathrm{ZnO}$ comerciais foram preparados a partir de calcinações em mufla durante $3,5 \mathrm{~h}$ em intervalos de $400 \mathrm{a}$ $1100{ }^{\circ} \mathrm{C}$, e deixado em dessecador por $24 \mathrm{~h}$. $\mathrm{O} \mathrm{TiO}_{2}$ comercial utilizado, provavelmente a forma rutilo de custo mais acessível, não tinha especificações em relação a sua forma reticular, e as investigações foram conduzidas utilizando este material para comparações com a forma anatase.

Os objetivos das calcinações foram a eliminação de resíduos presentes no material e a verificação de possíveis mudanças reticulares que poderiam ocorrer na estrutura do catalisador ${ }^{16}$. Entre as formas 
reticulares assumidas pelo $\mathrm{TiO}_{2}$ (rutilo e anatase), a forma rutilo era menos fotoativa comparando-se com a anatase ${ }^{17}$.

\section{Monitoramento do efluente}

As análises da DQO do efluente in natura, após a coagulação e floculação da matéria orgânica e também após o tratamento fotoquímico, foram realizadas pelo método calorimétrico de digestão de refluxo fechado, utilizando-se as soluções de dicromato de potássio, sulfato de mercúrio, e solução de biftalato ácido de potás$\operatorname{sio}^{18}$.

Os compostos aromáticos foram investigados pelas absorções na região de $280 \mathrm{~nm}$ e no infravermelho na região de $1600 \mathrm{~cm}^{-1}$ que são utilizadas para a identificação de ligninas em diferentes tipos de madeiras ${ }^{19,20}$. Para verificar a degradação do efluente por infravermelho, foram coletadas $100 \mathrm{~mL}$ do efluente após a floculação/coagulação e $100 \mathrm{~mL}$ após o tratamento fotoquímico, colocadas em estufa a $60{ }^{\circ} \mathrm{C}$ para a lenta evaporação da água, obtendo-se assim um resíduo seco para a confecção das pastilhas de $\mathrm{KBr}$. As absorções relacionadas ao grupo carbonila foram observadas entre 1750 e $1600 \mathrm{~cm}^{-1}$, enquanto que as bandas mais importantes e relacionadas às vibrações do grupo aromático foram monitoradas no intervalo entre $1600 \mathrm{a} 1510 \mathrm{~cm}^{-1}$. As diferenças entre as relações de intensidades dos picos e as respectivas áreas entre as bandas, foram utilizadas para a diferenciação dos tipos de ligninas ${ }^{20,21}$.

As macromoléculas e os fragmentos do efluente, após os tratamentos primário e fotoquímico, foram investigadas no aparelho para ultrafiltração (Nicon 8050), com membranas Spectrum de 100.000; $50.000 ; 30,000 ; 10,000 ; 3.000 ; 1.000$ e 500 Daltons. Para não inviabilizar a técnica de ultrafiltração, o efluente foi previamente filtrado em papel de filtro Whatman $\mathrm{n}^{\circ} 5$ para reter as finas partículas e evitar o entupimento das membranas.

\section{RESULTADOS E DISCUSSÃO}

Na Tabela 1 aparecem os valores de $\mathrm{pH}$ das amostras dos efluentes in natura, os valores ótimos de $\mathrm{pH}$ para a floculação e coagulação, as concentrações do sulfato de alumínio utilizadas nos estudos pelo teste de jarros, e as respectivas absorvâncias do efluente in natura e do sobrenadante após a floculação e coagulação. Pelos dados da tabela, observou-se uma redução significativa dos compostos aromáticos pela floculação e coagulação com o sulfato de alumínio. Na Figura 3 aparecem as absorvâncias em $\lambda=280 \mathrm{~nm}$, utilizando-se o sulfato de alumínio como coagulante e a presença de polieletrólitos naturais, em diferentes concentrações, como auxiliares de coagulação. Observou-se que a concentração ótima do polieletrólito foi de $0,5 \mathrm{mg} \mathrm{L}^{-1}$, com a redução significativa da absorção em $280 \mathrm{~nm}$ em relação à redução provocada somente pelo sulfato de alumínio. Por outro lado, a elevação nas concentrações do polieletrólito não melhorou de forma significativa a redução nas absorções em $280 \mathrm{~nm}$.

A Figura 4 mostra os resultados das absorvâncias em 280nm e os respectivos valores de $\mathrm{pH}$, versus o tempo de irradiação com lâm-

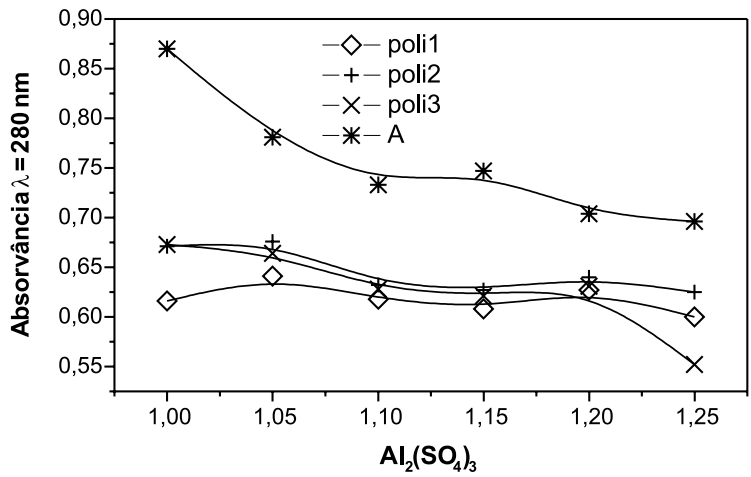

Figura 3. Absorvâncias dos efluentes do canal de branqueamento em função da concentração do $\mathrm{Al}_{2}\left(\mathrm{SO}_{4}\right)_{3}$ e dos polieletrólitos naturais extraídos do cactus Cereus peruvianus, em intervalos de $\mathrm{pH}$ 6,5 a 7,5, ajustados com soluções de $\mathrm{H}_{2} \mathrm{SO}_{4} 0,1 \mathrm{~mol} \mathrm{~L}^{-1}$ e $\mathrm{NaOH} \mathrm{0,1} \mathrm{mol} \mathrm{L} L^{-1}$. A = solução de $\mathrm{Al}_{2}\left(\mathrm{SO}_{4}\right)_{3}$; poli1 $=\mathrm{Al}_{2}\left(\mathrm{SO}_{4}\right)_{3}+0,5 \mathrm{mg} \mathrm{L}^{-1}$ do polieletrólito natural; poli2 $=\mathrm{Al}_{2}\left(\mathrm{SO}_{4}\right)_{3}+$ $1,6 \mathrm{mg} \mathrm{L}^{-1}$ do polieletrólito; poli3 $=\mathrm{Al}_{2}\left(\mathrm{SO}_{4}\right)_{3}+2,7 \mathrm{mg} \mathrm{L}^{-1}$ do polieletrólito

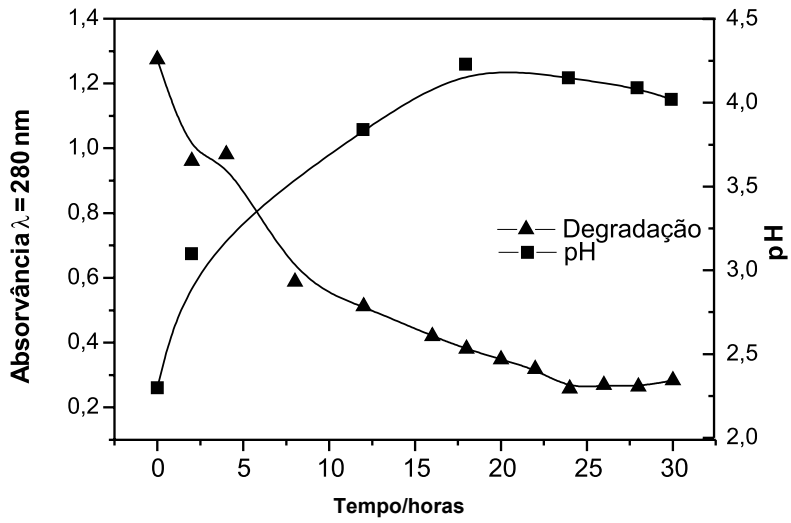

Figura 4. Dependência das absorvâncias e o pH da solução em função do tempo de irradiação em horas, com lâmpada de $120 \mathrm{~W}$ e o $\mathrm{TiO}_{2}$ (anatase) calcinado a $600^{\circ} \mathrm{C}$ como catalisador. No início do experimento o $\mathrm{pH}$ da solução foi ajustado a $\mathrm{pH} \sim 2,3$ com a solução de $\mathrm{H}_{2} \mathrm{SO}_{4} 0,1 \mathrm{~mol} \mathrm{L^{-1 }}$

pada de $120 \mathrm{~W}$. Observou-se que à medida que ocorreu a degradação da substância, ocorreu também uma elevação significativa do $\mathrm{pH}$ da solução. Embora as inclinações das curvas sejam menos acentuadas, os testes com lâmpadas de $16 \mathrm{~W}$ e outras lâmpadas mostraram também a mesma tendência. As diminuições das absorções com o tempo de irradiação e a elevação gradativa do $\mathrm{pH}$ das soluções indicaram que, provavelmente, ocorreu a formação de íons hidroxilas em solução, ou o consumo de íons hidrogênios na geração de substâncias pela fragmentação das macromoléculas.

Na Figura 5 aparecem as curvas de absorções obtidas a partir da adição do fenol (composto modelo) na calha de tratamento e

Tabela 1. pH e absorvâncias antes ( in natura) e após o tratamento por floculação/coagulação em teste de jarros*

\begin{tabular}{lccccc}
\hline $\begin{array}{l}\text { Amostras } \\
\text { (Canais) }\end{array}$ & $\begin{array}{c}\mathrm{pH} \\
\text { (in natura })\end{array}$ & $\begin{array}{c}\mathrm{pH} \text { ótimo } \\
\text { teste de jarros }\end{array}$ & $\begin{array}{c}\mathrm{Al}_{2}\left(\mathrm{SO}_{4}\right)_{3} \\
\left(\mathrm{mg} \mathrm{L}^{-1}\right)\end{array}$ & \multicolumn{2}{c}{$\begin{array}{c}\text { Absorvâncias }(\lambda=280 \mathrm{~nm})^{* * *} \\
\text { in natura }\end{array}$} \\
\hline Branqueamento & 8,2 & $(6,7$ a 7,4$)$ & 1.180 & 1,64 & 0,889 \\
Central & 7,4 & $(7,0$ a 7,6$)$ & 1.300 & 1,39 & 0,745 \\
\hline
\end{tabular}

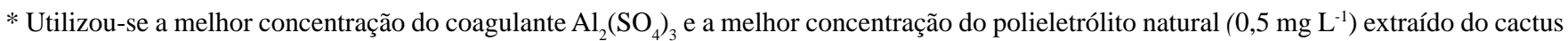
Cereus peruvianus. ** Resultados confirmados pelas analises da DQO do efluente (in natura) e para o sobrenadante após o teste de jarros 


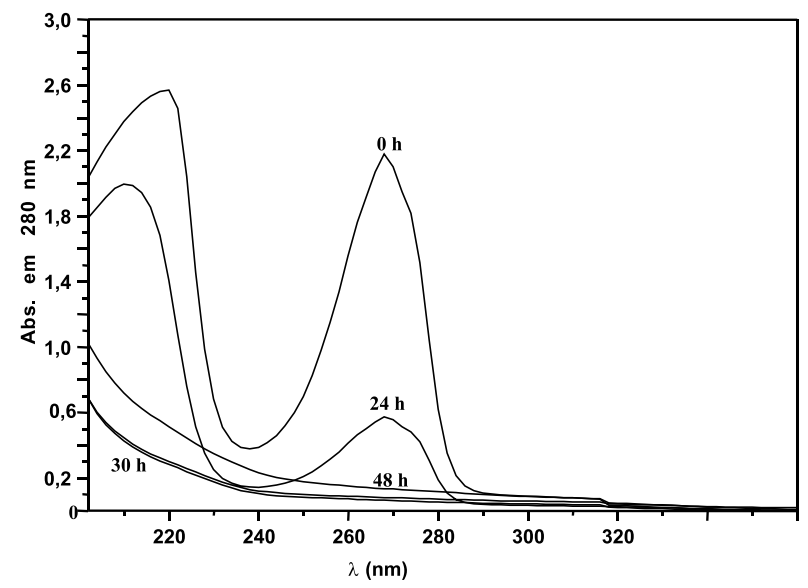

Figura 5. Dependência das absorvâncias da solução durante o processo fotodegradativo, após a adição do fenol. Início = tempo zero de irradiação; outras curvas = após 24, 48 e 60 h de irradiação com lâmpadas de $120 \mathrm{~W}$ e o $\mathrm{TiO}_{2}$ (anatase) calcinado a $600{ }^{\circ} \mathrm{C}$ como catalisador

monitoradas durante $50 \mathrm{~h}$. Observou-se que com $48 \mathrm{~h}$ de irradiação a degradação do efluente do canal de branqueamento foi praticamente total, observada através das análises da DQO, com decréscimo acentuado na banda de absorção em 250-280 nm. Em outro experimento, o efluente do canal de branqueamento foi submetido à irradiação com lâmpadas de $120 \mathrm{~W}$, utilizando-se o $\mathrm{TiO}_{2}$ (anatase) calcinado a $600{ }^{\circ} \mathrm{C}$ como catalisador. Após $50 \mathrm{~h}$ de irradiação sobre o efluente, adicionouse a solução de fenol $5 \times 10^{-3} \mathrm{~mol} \mathrm{~L}^{-1}$, continuando-se a irradiação até $120 \mathrm{~h}$. O comportamento fotodegradativo do fenol foi semelhante aos compostos dos derivados de ligninas contidos no efluente. Entretanto, a degradação do fenol foi mais lenta comparando-se ao efluente investigado. $\mathrm{O}$ tempo de degradação para o efluente foi de aproximadamente 48 h, e 96 h para a solução após a adição do fenol, com a diminuição da DQO da solução em aproximadamente $90 \%$, conforme os resultados que aparecem na Tabela 2 .

Entre os diferentes catalisadores investigados, o $\mathrm{TiO}_{2}$ (anatase) calcinado a $600{ }^{\circ} \mathrm{C}$ por $4 \mathrm{~h}$ foi cerca de $25 \%$ mais eficiente $(\mathrm{p}=0,05)$ que o $\mathrm{TiO}_{2}$ (comercial) calcinado a $1.100{ }^{\circ} \mathrm{C}$ durante $4 \mathrm{~h}$, sendo estes
50 a $70 \%$ mais eficientes que o $\mathrm{TiO}_{2}$ calcinado a outras temperaturas $\left(900,600\right.$ e $\left.400{ }^{\circ} \mathrm{C}\right)$ respectivamente. Por outro lado, utilizando-se o $\mathrm{ZnO}$ como catalisador, a irradiação com a lâmpada BLB de $18 \mathrm{~W}$ foi $30 \%$ mais eficiente $(\mathrm{p}=0,05)$ que a lâmpada UVC de $18 \mathrm{~W}$. Utilizando-se o $\mathrm{TiO}_{2}$ (anatase) calcinado a $600^{\circ} \mathrm{C}$ a eficiência da degradação do catalisador na concentração de $1 \mathrm{~g} \mathrm{~L}^{-1}$ foi semelhante ao mesmo catalisador na concentração de $2 \mathrm{~g} \mathrm{~L}^{-1}$, indicando que a partir de $1 \mathrm{~g} \mathrm{~L}^{-1}$, a elevação da concentração do catalisador não melhora significativamente a eficiência do processo. Por estas razões, utilizou-se o $\mathrm{TiO}_{2}$ (anatase) calcinado a $600{ }^{\circ} \mathrm{C}$ na concentração de $1 \mathrm{~g} \mathrm{~L}^{-1}$ como catalisador nos demais experimentos.

Nos estudos de ultrafiltrações foram observados degradações da ordem de $17 \%$ nas macromoléculas com peso molecular acima de $100 \mathrm{kDa}$, e degradações de 12 a $45 \%$ nas macromoléculas com peso molecular de 1000 e 500 Da. Na Figura 6 aparecem os resultados finais das diferentes etapas de tratamento. Os resultados são comparados considerando-se a concentração da DQO inicial como $100 \%$, observado na coluna 1 da Figura 6 (efluente in natura). A coluna 2

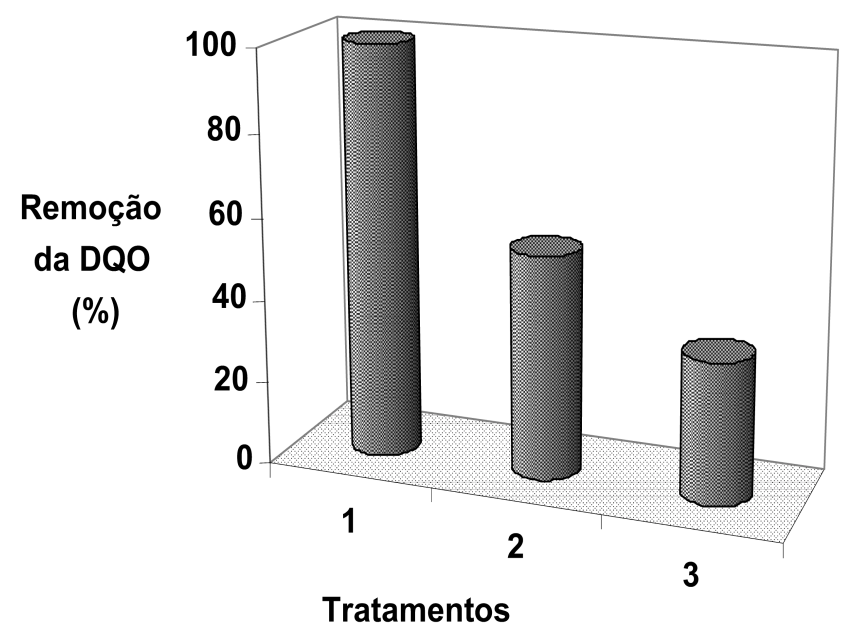

Figura 6. Remoção da DQO em (\% $)^{18}$ em função dos tratamentos realizados. 1) $D Q O$ do efluente in natura. 2) $D Q O$ do sobrenadante do efluente após os testes de jarros (floculação/coagulação). 3) DQO do sobrenadante após o tratamento fotoquímico

Tabela 2. Absorvâncias do efluente de branqueamento* e os respectivos valores em \% de DQO remanescente em solução, em função do tempo de irradiação, antes e após a adição da solução de fenol

\begin{tabular}{|c|c|c|c|}
\hline $\begin{array}{c}\text { Tempo de irradiação } \\
\text { (horas) }\end{array}$ & $\begin{array}{l}\text { Absorvância em } 280 \mathrm{~nm} \\
\text { do efluente }\end{array}$ & $\begin{array}{l}\text { Absorvância após } \\
\text { a adição de fenol }\end{array}$ & $\begin{array}{c}\text { \% da DQO da } \\
\text { solução }\end{array}$ \\
\hline 0 & 2,00 & ………..... & 100 \\
\hline 5 & 1,30 & ……......... & 65 \\
\hline 10 & 0,70 & ……......... & 35 \\
\hline 20 & 0,40 & ……........ & 20 \\
\hline 25 & 0,20 & ……......... & 10 \\
\hline 40 & 0,15 & ………..... & 7,5 \\
\hline 48 & 0,15 & …….......... & 7,5 \\
\hline 50 & .......... & 2,00 & 100 \\
\hline 60 & .......... & 1,40 & 70 \\
\hline 70 & ......... & 0,90 & 45 \\
\hline 80 & $\ldots \ldots \ldots$ & 0,60 & 30 \\
\hline 90 & $\ldots \ldots \ldots$ & 0,30 & 15 \\
\hline 96 & ......... & 0,20 & 10 \\
\hline 120 & ......... & 0,20 & 10 \\
\hline
\end{tabular}

(*) Efluente do branqueamento com $\mathrm{pH}$ inicial ajustado a 5,8 $\pm 0,2$ e $\mathrm{pH}$ final observado de 7,4 $\pm 0,2$. As amostras foram irradiadas com lâmpadas de $120 \mathrm{~W}$, utilizando como catalisador o $\mathrm{TiO}_{2}$ (anatase) previamente calcinado a $600{ }^{\circ} \mathrm{C}$. 
corresponde à concentração da DQO após o tratamento por floculação e coagulação, e a coluna 3 à DQO após o tratamento fotoquímico. Em termos percentuais, a DQO remanescente após a floculação e coagulação foi de $54 \%$ e $34 \%$ após o tratamento fotoquímico, em um tempo relativamente curto de 14 a 15 h de irradiação. Estes resíduos orgânicos remanescentes de $34 \%$, basicamente fragmentos das macromoléculas iniciais, podem ainda ser degradados se forem submetidos ao tratamento biológico por lodos ativados ${ }^{9}$. Com um tempo mais prolongado de irradiação, por exemplo $>48 \mathrm{~h}$, a DQO remanescente pode ser menor que $10 \%$, conforme os dados da Tabela 2. Entretanto, em função do volume de efluentes da indústria papeleira e o tempo de retenção necessário, estas condições são difíceis de serem aplicadas em situações reais. Portanto, por razões práticas, considerou-se a remoção de $66 \%$ da DQO nas etapas de floculação/ coagulação e degradação fotoquímica.

\section{CONCLUSÃO}

O procedimento proposto para a remoção de derivados de ligninas em efluentes das indústrias de papel e celulose pela floculação/coagulação e, a seguir, pela fotodegradação catalítica, utilizando-se o $\mathrm{TiO}_{2}$ (anatase) calcinado a $600{ }^{\circ} \mathrm{C}$ como catalisador, mostrou ser eficiente na remoção de aproximadamente $66 \%$ destes compostos refratários. A etapa de floculação/coagulação é muito importante para a redução do tempo de irradiação necessário ao tratamento fotocatalítico. O teste de ultrafiltração mostrou que os compostos remanescentes são basicamente fragmentos das macromoléculas iniciais, e podem ser degradadas biologicamente em uma etapa posterior.

\section{AGRADECIMENTOS}

Ao CNPq e à Fundação Araucária - PR pelo suporte financeiro.

\section{REFERÊNCIAS}

1. Gabardo Filho, H.; Barros, M. J.; Filho, H.G.; Reis, E.M.; Nozaki, J.; $24^{a}$. Reunião Anual da Sociedade Brasileira de Química, Poços de Caldas, Brasil, 2001.

2. D’Almeida, M.L.O.; Celulose e papel, tecnologia de fabricação da pasta celulósica, São Paulo, 2 ed., II, Escola Senai Theobaldo de Nigris, Depto. Regional de São Paulo, IPT - Centro Técnico de Celulose e Papel, 1988.

3. Freire, R.S.; Pelegrini, R.; Kubota, L.T.; Duran, N.; Peralta-Zamora, P.; Quim. Nova 2000, 23, 504.

4. Villasenor, J.; Reyes, P. P.; J. Chem. Technol. Biotechnol. 1996, 8, 105.

5. Pulgarin, C.; Kiwi, J.; Chimia 1996, 50, 50.

6. Perez, D.S.; Castellan, A.; Grelier, S. G. H.; Machado, A. E. H.; Ruggiero, R.; Vilarinho, A.L.; J. Photochem. Photobiol. Chem. 1998, 115, 73.

7. Oliveira, M.A.; Reis, E.M.; Nozaki, J.; Wat., Air, Soil Poll. 2001, 126, 307.

8. Oliveira, M. A.; Reis, E.M.; Nozaki, J.; Environ. Res. 2001, 85, 177.

9. Reis, E. M.; Nozaki, J.; Braz. Arch. Biol. Technol. 2000, 43, 125.

10. Silva Perez, D.; Castellan, A.; Grelier, S.; Terrones, M.G.H.; Machado, A.E.H.; Ruggiero, R.; Vilarinho,A.L.; J. Photochem. Photobiol.Chem. 1998, 115,73 .

11. Machado, E. H.; Ruggiero, R.; Nourmamode, A.; Grelier, S.; Terrones, M. G. H.; Chemosphere 2000, 40, 115.

12. Resat, A.; Hugul, M.; J. Chem. Technol. Biotechnol. 1996, 67, 221.

13. Chen, D.E.; Ray, A. K.; Water Res. 1998, 32, 3223.

14. Khalil, M. M. H.; Int. J. Photoenergy 1999, $1,1$.

15. Trillas, M.; Peral, J.; Doménech, X.; J. Chem. Technol. Biotechnol. 1996, 67, 237.

16. Kurokawa, Y.; Ota, H.; Sato, T.; J. Mater. Sci. Lett. 1994, 13, 516.

17. Ziolli, R. L; Jardim, W. F.; Quim. Nova 1998, 21, 196.

18. APHA - AWWA - WPCF. Standard Methods for the Examination of Water and Wastewater, $18^{\text {th }}$ ed., Washington, 1989, p. 2560.

19. Fengel, D.; Wegener, G.; Wood, Chemistry, Ultrastructure, Reactions, Walter de Gruyter \& Co: New York, 1989, p. 162.

20. Hergert, H.L.; Henrrick, F.W. Em Recent Advances in Phytochemistry; Plenun Press: New York, London, 1977, v. 11, p. 443.

21. Gouvêa, C.A.K.; Wypych, F.; Moraes, S.G.; Duran, N.; Nagata, N.; PeraltaZamora, P.; Chemosfere 2000, 40, 433. 